\title{
MULTICRITERIA DECISION GROUP MODEL FOR THE SELECTION OF SUPPLIERS
}

\author{
Luciana Hazin Alencar* \\ Adiel Teixeira de Almeida \\ Federal University of Pernambuco (UFPE) \\ Recife - PE, Brazil \\ lhazin@ufpe.br \\ * Corresponding author / autor para quem as correspondências devem ser encaminhadas \\ Recebido em 08/2007; aceito em 03/2008 após 1 revisão \\ Received August 2007; accepted March 2008 after one revision
}

\begin{abstract}
Several authors have been studying group decision making over the years, which indicates how relevant it is. This paper presents a multicriteria group decision model based on ELECTRE IV and VIP Analysis methods, to those cases where there is great divergence among the decision makers. This model includes two stages. In the first, the ELECTRE IV method is applied and a collective criteria ranking is obtained. In the second, using criteria ranking, VIP Analysis is applied and the alternatives are selected. To illustrate the model, a numerical application in the context of the selection of suppliers in project management is used. The suppliers that form part of the project team have a crucial role in project management. They are involved in a network of connected activities that can jeopardize the success of the project, if they are not undertaken in an appropriate way. The question tackled is how to select service suppliers for a project on behalf of an enterprise that assists the multiple objectives of the decision-makers.
\end{abstract}

Keywords: group decision; selection of suppliers; ELECTRE IV; VIP Analysis.

\section{Resumo}

Vários autores têm estudado decisão em grupo nos últimos anos, o que indica a relevância do assunto. Esse artigo apresenta um modelo multicritério de decisão em grupo baseado nos métodos ELECTRE IV e VIP Analysis, adequado aos casos em que se tem uma grande divergência entre os decisores. Esse modelo é composto por dois estágios. No primeiro, o método ELECTRE IV é aplicado e uma ordenação dos critérios é obtida. No próximo estágio, com a ordenação dos critérios, o método VIP Analysis é aplicado e as alternativas são selecionadas. Para ilustrar o modelo, uma aplicação numérica no contexto da seleção de fornecedores em projetos é realizada. Os fornecedores que fazem parte da equipe do projeto têm um papel fundamental no gerenciamento de projetos. Eles estão envolvidos em uma rede de atividades conectadas que, caso não sejam executadas de forma apropriada, podem colocar em risco o sucesso do projeto. A questão colocada é como selecionar fornecedores de serviço para um projeto de uma empresa considerando os objetivos dos decisores envolvidos.

Palavras-chave: decisão em grupo; seleção de fornecedores; ELECTRE IV; VIP Analysis. 


\section{Introduction}

Project management has been the target of a great variety of studies in recent years. Therefore, there has been an increase in the need for qualified suppliers committed to the client's objectives and who are capable of undertaking them. They play crucial roles in project management, being involved in a network of connected activities that, if not developed appropriately, can jeopardize the success of the project. They are present throughout the life cycle of the project, though not necessarily simultaneously in all of its stages, and they are responsible for its planning, execution and control.

The selection of suppliers who will be part of the project team in a project is a decisive event for its success. Several methodologies regarding this subject have been drawn up in recent years which show the relevance of the theme. Among the methodologies presented, there are few that consider a selection approach with all the participants in an integrated way and that pay special attention to tackling decision-makers' preferences.

Therefore, this paper presents a multicriteria group decision model for the selection of suppliers in projects, based on VIP Analysis and ELECTRE IV methods. This model is appropriate for those cases where there is great divergence among the decision makers.

This paper has been structured into five sections: Section 1 contextualizes project management with emphasis on the selection of project team members, and also defines the objective of the paper; Section 2 presents the general questions inherent in selecting suppliers in a project; Section 3 presents an overview of VIP Analysis and ELECTRE IV multi-criteria methods; Section 4 presents the general questions in group decision; Section 5 shows the structuring of the typical problem of selecting suppliers in projects; Section 6 presents the multi-criteria group decision model aggregating the weightings of the decision-makers on the criteria; finally, in Section 7, the conclusions of the study are presented.

\section{The Selection of Suppliers in a Project}

Project management can be defined as the planning, monitoring and control of all the aspects of a project and the motivation of all those involved in reaching the objectives of the project in time, cost, quality and desired performance (BSI, 2000).

Project management has been studied by two Associations which are very familiar to professionals that are active in this area, the PMI (Project Management Institute) and the IPMA (International Project Management Association), besides other Associations, in general related to Production Engineering (Operational Research and Management Science) such as: INFORMS, Decision Science Institute and IFORS.

According to the PMI (2004), project management involves nine managerial fields: time, cost, human resources, quality, procurement, scope, communication, integration and risk management. All of them must be managed and integrated de facto.

Still according to the PMI (2004), the procurement management for a project includes processes for buying or acquiring the products or services needed for carrying out the work. Among the processes are planning purchases and acquisitions, plan contracting, supplier responses, select suppliers, contract administration and contract closure. The process of selecting suppliers is what this paper focuses on.

In this process, proposals are received and evaluation criteria are applied in order to select one or more suppliers who are qualified and acceptable. 
Among the various techniques for selecting a supplier, the PMI (2004) presents the system of weighting, independent estimates, the system of sifting, the systems of classifying suppliers and the opinion of specialists.

The suppliers selected are those considered in a competitive band, based on the result of the bid or the evaluation of the tender, and who have negotiated a preliminary version of the contract.

Smith (1991) states two methods for selecting a supplier: competitive tender and negotiation. In both cases, the criterion generally used is price.

In Brazil going out to tender is governed by Law 8.666/93 (altered by Laws 8.883/94 and 9.648/98). In the public sector of the United Kingdom, the predominant type of tendering, very nearly the exclusive one, is tendering based on competition, the contract being guaranteed to the bidder making the bid with the lowest price (Brown, 2003). Tendering based on competition can be selective and open.

The system of open tendering allows any Company to submit a bid for the project (Merna \& Smith, 1990). The invitations to take part in tendering are open to all Companies of the sector, whether they be large or small, by means of advertising the tender in mass circulation newspapers and journals specific to the sector. Thus, the client wishes to obtain the largest possible number of tenders, so as to raise competition to the maximum, and, consequently, to obtain the lowest bid.

As to selective tendering, this is a much used method in order to eliminate unsatisfactory proposals. In this process, it is necessary to assess the qualifications of the bidder, in accordance with the criteria judged important, in the case of private Companies or the criteria laid down under the prevailing law, in the case of public tendering.

Several models have been drawn up for selecting suppliers. Some of them use multi-criteria decision aid and others multi-criteria group decision aid (Hsieh et al., 2004; $\mathrm{Ng} \&$ Chow, 2004; Cheung et al., 2002;. Zavadskas \& Vilutiene, 2006; Singh \& Tiong, 2005; Pongpeng \& Liston, 2003; Al-Reshaid \& Kartam, 2005).

\section{Multi-criteria Methods}

Considering the importance of multi-criteria methods in dealing with human reality, several approaches have been proposed. All of them replace the search for the optimal solution for those of greatest commitment. They are used to support people and organizations to make decisions.

In this paper the methods used are VIP Analysis (Clímaco \& Dias, 2005), and ELECTRE IV (Roy \& Hugonard, 1992).

\section{- Variable Interdependent Parameters - VIP Analysis}

The purpose of VIP Analysis is to support the evaluation of a group of discrete alternatives, with a view to choosing the most favored, in agreement with the multi-attribute addictive function (Clímaco \& Dias, 2005). The global value of an alternative $a_{i}$ is the sum of their values for the $n$ criteria $\left(v_{1}\left(a_{1}\right), \ldots, v_{n}\left(a_{i}\right)\right)$, weighted by $n$ scalar weights $k=\left(k_{1}, \ldots, k_{n}\right)$ :

$$
V\left(a_{i}, k\right)=\sum_{j=1}^{n} k_{j} v_{j}\left(a_{i}\right), \quad \text { with } \sum_{j=1}^{n} k_{j}=1 \text { and } k_{j} \geq 0 .
$$


One of the most difficult parts of the decision process is the determination of those parameters, since they will reflect the preferences and the trade-offs of the decision-maker. However, apart from it being difficult for the decision-maker's findings to provide the necessary information about their preferences, those preferences can change as the decision process grows, in addition to which they frequently diverge in group decision situations.

The partial pieces of information in this method are concerned only with the parameters of importance $k=\left(k_{1}, k_{2} \ldots, k_{n}\right)$. These parameters are functions of the criteria $\mathrm{C}_{\mathrm{n}}$ as well as of the range over which they will be allowed to vary. Assuming that the constraints which define $K$ are linear, they can limit the weights by means of upper and lower limits, besides which it is possible the weights may be related among themselves, thus imposing an ordering defined by the decision-maker and constraints on trade-offs. Respectively, these constraints can be of the type:

$$
\begin{aligned}
& l_{j} \leq k_{j} \leq L_{j} \\
& k_{1} \leq k_{2} \\
& \frac{k_{2}}{k_{1}} \geq 0,5
\end{aligned}
$$

Thus, if the decision maker is in doubt about determining the necessary values of the weights, he may find it easier to order them, for instance. $\mathrm{K}$ denotes the group of all the combinations of the values of the parameters that satisfy all the established constraints.

The results obtained by VIP for a group $\mathrm{K}$ of combinations of values for the parameters of importance and a set $\mathrm{A}=\left\{a_{1}, \ldots, a_{m}\right\}$ of alternatives include (Dias \& Clímaco, 2000):

- A variation interval of values for each alternative $a_{i}$, from the $\min \left\{V\left(a_{i}, k\right): k \in K\right\}$ to the $\max \left\{V\left(a_{i}, k\right): k \in K\right\}$.

- The greatest difference in value for each ordered pair of alternatives $\left(a_{i}, a_{j}\right) \in A^{2}$, namely, $\max \left\{V\left(a_{i}, k\right)-V\left(a_{j}, k\right): k \in K\right\}$.

- For each alternative $a_{i} \in A$, the maximum regret associated with choosing it, namely, the maximum difference of the value considering the alternatives which can have a higher value than $a_{i}$ given $K$ :

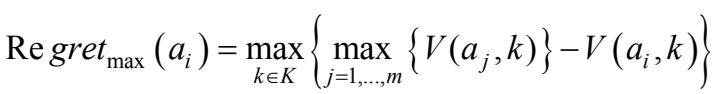

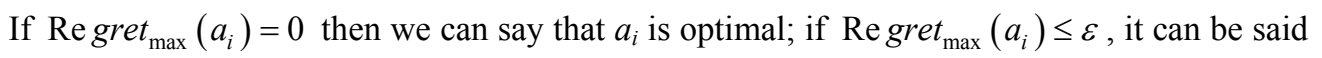
that $a_{i}$ is quasi-optimal with tolerance $\varepsilon$.

Undertaking a sensitivity analysis a posteriori for the weights is not necessary, since all the combinations considered acceptable to the decision-maker are investigated, which makes it possible to obtain a more robust conclusion.

\section{- ELECTRE IV}

The ELECTRE IV method (Roy \& Hugonnard, 1982) is based on a family of pseudocriteria, the objective of which is to order alternatives without introducing any matter to be 
weighted among these criteria (Vincke, 1992). It can be said that, generally, the structure of this method is simpler than that of others of the ELECTRE family, since, like ELECTRE III, uses the criteria associated with a preference threshold $(p)$ and with an indifference threshold $(q)$, instead of using the notions of concordance and discordance (Gomes et al., 2004).

The outranking ratios are then defined by direct reference to the levels of performance of the alternatives. Two outranking ratios are constructed: Strong Outranking $\left(a \boldsymbol{S}^{F} b\right)$ and Weak Outranking $\left(a \boldsymbol{S}_{f} b\right)$.

Just as in ELECTRE III, exploring outranking ratios is conducted using the processes of ascending and descending distillation, thus resulting in the ranking of the alternatives from best to worst, the current method being simpler by the fact of there only being two levels of outranking. The concept of qualification is used based on the ratios of strong and weak outranking, in order to define the two modes of ranking. The initial qualification of the alternatives is determined by the ratio of strong outranking. The weak ratio is used to distinguish, if possible, among those alternatives which have the same value of initial qualification (Belton \& Stewart, 2002).

\section{Group Decision}

Negotiation and group decision processes are very complex human activities. Negotiation is a process of taking decisions jointly. It is direct or tacit communication, among individuals who are trying to establish an agreement for their mutual benefit (Young, 1991).

Jiménez \& Polasek (2003) present three different situations in this context: group decision, negotiated decision and systematic decision. In the first of these cases, all individuals are looking for a common objective. In the second, each individual solves the problem independently, and zones of agreement and disagreement between the different positions are found. Finally, in the third case, each individual acts independently but all the positions are met in accordance with the principle of tolerance.

It is important to point out that the type of group decision dealt with in this paper does not involve negotiation.

Currently, various authors have been studying group decision making, which indicates how relevant it is (Humphreys \& Garrick, 2006; Beynon, 2006; Matsatsinis et al., 2005; Easley et al., 2000; Clímaco \& Dias, 2005).

According to Jelassi et al. (1990), group decision-making is normally understood as the reduction of different individual preferences in a given set for a single collective preference.

Group decision problems involve different decision-makers. They may represent different departments of a Company, or different countries in an international organization, or simply different partners involved in a project. They may diverge in their perception of the problem and have different interests, but all are responsible for the well-being of the organization and share responsibility for the decision implemented.

When a situation of decision-making involves multiple actors, each with different values, the final decision is generally the result of an interaction between these individual preferences. Nevertheless, this insertion is not conflict-free, and may be caused by a great number of factors, such as for example, different ethical or ideological beliefs, different specific objectives or different roles within the organization (Roy, 1996; Leyva-López \& FernándezGonzález, 2003). 
At the start of the 1980s, various group decision support systems (GDSS) were drawn up to support decision-makers in a given context. The focus of many GDSS is targeted on structuring ideas, generating alternatives and procedures, with there being relatively few which use the multi-criteria group decision support methodology (Macharis \& Brans, 1998).

Leyva-López \& Fernández-González (2003) describe two approaches, which are generally used with multi-criteria decision support for aggregating the preferences of the group. In the first, the decision-makers should enter into an agreement regarding the alternatives, criteria, performances, weights, thresholds, and other parameters needed to reach a solution in accordance with the chosen problematic. Group discussion focuses on what actions and criteria should be considered and what weights and other necessary parameters are appropriate. Once the discussion is finalized and all the information is gathered in, a technique is used to obtain the values of the parameters of this model which should represent the collective opinion. With this information, a multi-criteria decision model supplies the solution for the group. Under the second approach, although the decision-makers may exchange opinions and relevant information, a group consensus is only needed to define a potential set of actions. Each member defines his/her own criterion, the appropriate evaluations and the models of the parameters (weights, thresholds, etc.) and a multi-criteria method is used to obtain personal ranking. Thereafter, each actor's criterion is considered separately, and the information contained in his/her individual is aggregated into a final collective order, using this self-same multi-criteria decision approach or another one.

These authors developed ELECTRE GD, which is an extension of ELECTRE III for group decision-making, using a genetic algorithm to explore the relation of outranking, which is derived from the ideas of ELECTRE related to concordance, discordance and incomparability.

Macharis \& Brans (1998) developed GDSS PROMETHEE, with the objective of supporting a group of decision-makers to find a consensus in relation to a set of possible alternatives. The method can be divided into three steps: the preliminary stage, that of individual evaluation and that of global evaluation.

Other methods have also been developed to tackle problems which involve group decisionmaking such as the AGAP System (Costa et al., 2003), ARGOS (Colson, 2000), VIP-G (Clímaco \& Dias, 2005), and so forth.

\section{Structuring the Typical Problem of Selecting Suppliers in Projects}

There follows a presentation of the typical problem used as a reference for the numerical application of the multi-criteria decision group selection model - therefore, this is a specific illustration and may not be applicable to other situations. This description includes the basic ingredients for the general structuring of the problem.

\subsection{Analysis of the client's objectives}

It is at this stage that the true expectations and objectives regarding the project are determined. The client's representatives define the formally required decision criteria to be used to select the suppliers.

First of all, the group of decision-makers representing the client is presented: 
- $\mathrm{D}_{1}$ - representative of the Dept of Engineering (technical engineer);

- $\mathrm{D}_{2}$ - representative of the Dept of Engineering (quality engineer);

- $\mathrm{D}_{3}$ - representative of the Dept of Engineering (security and environment engineer);

- $\mathrm{D}_{4}$ - representative of the Dept of Acquisitions (budget);

- $\mathrm{D}_{5}$ - representative of the Dept of Procurement (contract).

After being designated by their organization and in possession of the scope of the project, the decision-makers hold a meeting with the analyst in order to identify the criteria (qualifiers and bid winners) to be used in the selection process.

The identified qualifying criteria, used to filter the tendering Companies, are as follows:

- Responsibility: This refers to the conformity of the Company with regard to regulations and standards demanded; to the existence of a quality certificate (a Company with ISO 9001/2000 certification) and of a security and environmental policy.

- General experience: This is about the general experience of the construction firm measured in square meters over the last 5 (five) years; thus, all such companies should have at least five years' experience. The attributes used are: (a) the total of built square meterage by the construction company, (b) the total of square meterage in similar projects. The bidder who does not meet the minimum values specified will be eliminated from the process.

- Financial situation: This refers to the financial situation of the bidder. The attributes used are: general liquidity, current liquidity and general solvency. These indices are measured as shown in equations 6,7 and 8, respectively. The client will not accept bidders who may be in a financial situation below the limit stipulated - in general, these indices should be greater than 1 (one).

$$
\begin{aligned}
& \text { general liquidity }=\frac{\text { current assets }+ \text { assets realizable in the long term }}{\text { current liabilities }+ \text { liabilities realizable in the long term }} \\
& \text { current liquidity }=\frac{\text { current assets }}{\text { current liabilities }} \\
& \text { general solvency }=\frac{\text { total assets }}{\text { current assets }+ \text { liabilities realizable in long term }}
\end{aligned}
$$

Next, the winning bid criteria are presented. They are determined based on the results presented in the literature on similar problems and also take into account some interactions with project managers who are active in this context, so as to confirm their pertinence. The principles of coherence and independence among criteria are respected by the established family of criteria (Gomes et al., 2002).

They are:

- $\mathrm{Cr}_{1}-$ Cost: this refers to the need to ensure that budgets are not exceeded. This is measured in an objective way by the average of the cost deviations of the enterprise, carried out in the last 5 years in relation to the planned cost.

- $\mathrm{Cr}_{2}-$ Culture: this is related to the willingness to incorporate new ideas and concepts. 
- $\mathrm{Cr}_{3}$ - Design: this is in the sense of involving the construction companies and subcontractors who may have skills to help the project designers in their activities, thus producing a structure which is appropriate and a project which is stimulating intellectually.

- $\mathrm{Cr}_{4}-$ Quality: this aims to ensure that the quality of the project is effectively translated into physical quality and that it furnishes a structure which has low operational and maintenance costs.

- $\mathrm{Cr}_{5}$ - Time: this corresponds to the total period of the project and construction phase, to the skill at planning correctly and finalizing the activities in accordance with the deadlines laid down by the client. It is measured in an objective way by the average of the cost deviations of the projects (design) or of the enterprise, carried out in the last 5 (five) years, in relation to the initial schedule.

- $\mathrm{Cr}_{6}-$ Experience: this considers the experience of key people who will work in the enterprise, this being measured in terms of the years of experience of the engineers and project designers.

The evaluations of the criteria of culture, design and quality are measured in a subjective way by the analyst, through analyzing questionnaires and other information gathered in. It is the analyst who conducts the evaluations by the fact of this being about a technical evaluation of subjective judgments.

The attribution of weights to criteria should be made by the scaling constants (parameters associated with the degree of importance of the criteria), that indicate the value of tradeoffs between the various pairs of attributes. The range as well as importance must be reflected in any weight (Edwards \& Barron, 1994). As an illustration, consider the task of choosing which new car to buy. The price of the car is usually important. But would it still be important if the prices of all cars being considered ranged from $\$ 18,000$ to $\$ 18,100$ ? Clearly the degree of importance of an attribute depends on its spread (Edwards \& Barron, 1994). The identification of the anchors (reference performance levels) was considered for establishment of the evaluation of the scaling constants (Keeney, 1992; Gomes et al., 2002; Campos \& Almeida, 2006).

\section{Multicriteria Group Decision Model Aggregating the Weightings of the Decision- Makers on the Criteria}

This section presents a proposal for a group decision model, based on the ELECTRE IV and VIP Analysis methods, targeting cases in which a great divergence occurs between the decision-makers.

\subsection{Description of the Model}

One of the approaches used in group decision-making relates to the concordance among decision-makers in determining the alternatives, criteria, weights, thresholds and the other parameters needed for reaching a solution to the problem. Criticisms regarding this approach are in general associated with the fact that the parameters of the model, such as the weights and the thresholds for example, should represent a group consensus, whether it be unanimous or at least, by the large majority, which is not always possible, since divergences of opinions frequently occur, thus making it more difficult to fix values to the parameters. 
In the model proposed in this paper, each decision-maker determines his/her parameters; at the same time, they should determine the criteria and evaluate the alternatives in a collective way. Since the set of decision criteria is established by the group, comprising decisionmakers and the analyst, each decision-maker is responsible for his attribution of weights to the criteria and to the corresponding thresholds, according to his/her own value judgment. Therefore, the set of criteria is represented by the decision-makers and the set of alternatives through the criteria considered in the selection process.

That is $A=\left\{C r_{1}, C r_{2}, \ldots, C r_{i}, \ldots, C r_{n}\right\}$ the set of alternatives considered in the decision-making process and $C=\left\{D_{1}, D_{2}, \ldots, D_{j}, \ldots, D_{k}\right\}$ the set of criteria considered in the first step of the model. The matrix of evaluation is given as per Table 1 below:

Table 1 - Matrix of evaluation.

\begin{tabular}{ccccccc}
\hline & $\mathrm{D}_{1}$ & $\mathrm{D}_{2}$ & $\ldots$ & $\mathrm{D}_{\mathrm{j}}$ & $\ldots$ & $\mathrm{D}_{\mathrm{k}}$ \\
\hline $\mathrm{Cr}_{1}$ & $p_{11}$ & $p_{12}$ & $\ldots$ & $p_{1 j}$ & $\ldots$ & $p_{1 k}$ \\
$\mathrm{Cr}_{2}$ & $p_{21}$ & $p_{22}$ & $\ldots$ & $p_{2 j}$ & $\ldots$ & $p_{2 k}$ \\
$\ldots$ & $\ldots$ & $\ldots$ & $\ldots$ & $\ldots$ & $\ldots$ & $\ldots$ \\
$\mathrm{Cr}_{\mathrm{i}}$ & $p_{i 1}$ & $p_{i 2}$ & $\ldots$ & $p_{i j}$ & $\ldots$ & $p_{i k}$ \\
$\ldots$ & $\ldots$ & $\ldots$ & $\ldots$ & $\ldots$ & $\ldots$ & $\ldots$ \\
$\mathrm{Cr}_{\mathrm{n}}$ & $p_{n 1}$ & $p_{n 2}$ & $\ldots$ & $p_{n j}$ & $\ldots$ & $p_{n k}$ \\
\hline
\end{tabular}

During this first stage, the model involves the use of the ELECTRE IV method, which tackles problems which are modeled by a family of pseudo-criteria. These use few pieces of information and, consequently, its results furnish less information. Nevertheless, this method is very appropriate because of the way that the decision group is being dealt with in this model, for it is based on a non-compensatory logic, in which the criteria (decision-makers) are compared one by one and are not aggregated. In addition, it allows for dealing coherently with problems in which it is difficult to establish the weights of the criteria, represented in the actual case by the decision-makers. The concept of degree of outranking is not used because there is no information on the criteria. The outranking ratio is defined by direct reference to the performances of the alternatives, the outranking ratios being defined as strong and weak. As the final result, there is the ranking of the alternatives, represented in this model by the criteria of the decision-making process.

Once the criteria ranking has been obtained, the model moves into its second stage. In this stage, the following information is available:

- Set of alternatives.

- Set of criteria.

- Criteria ranking.

- Performance of the alternatives in relation to the criteria.

Given such information, VIP Analysis is an appropriate method to be used, since it suggests that the parameters (scale constants or weights) are treated as interdependent variables subject to constraints imposed by the structure of the method used. Therefore, it is not necessary to fix a precise value for the parameters, the establishment of an ordering among 
the criteria being sufficient, in accordance with what has been obtained in the previous step, and the fixation of upper and lower limits for each weight.

The model can be presented as in Figure 1 .

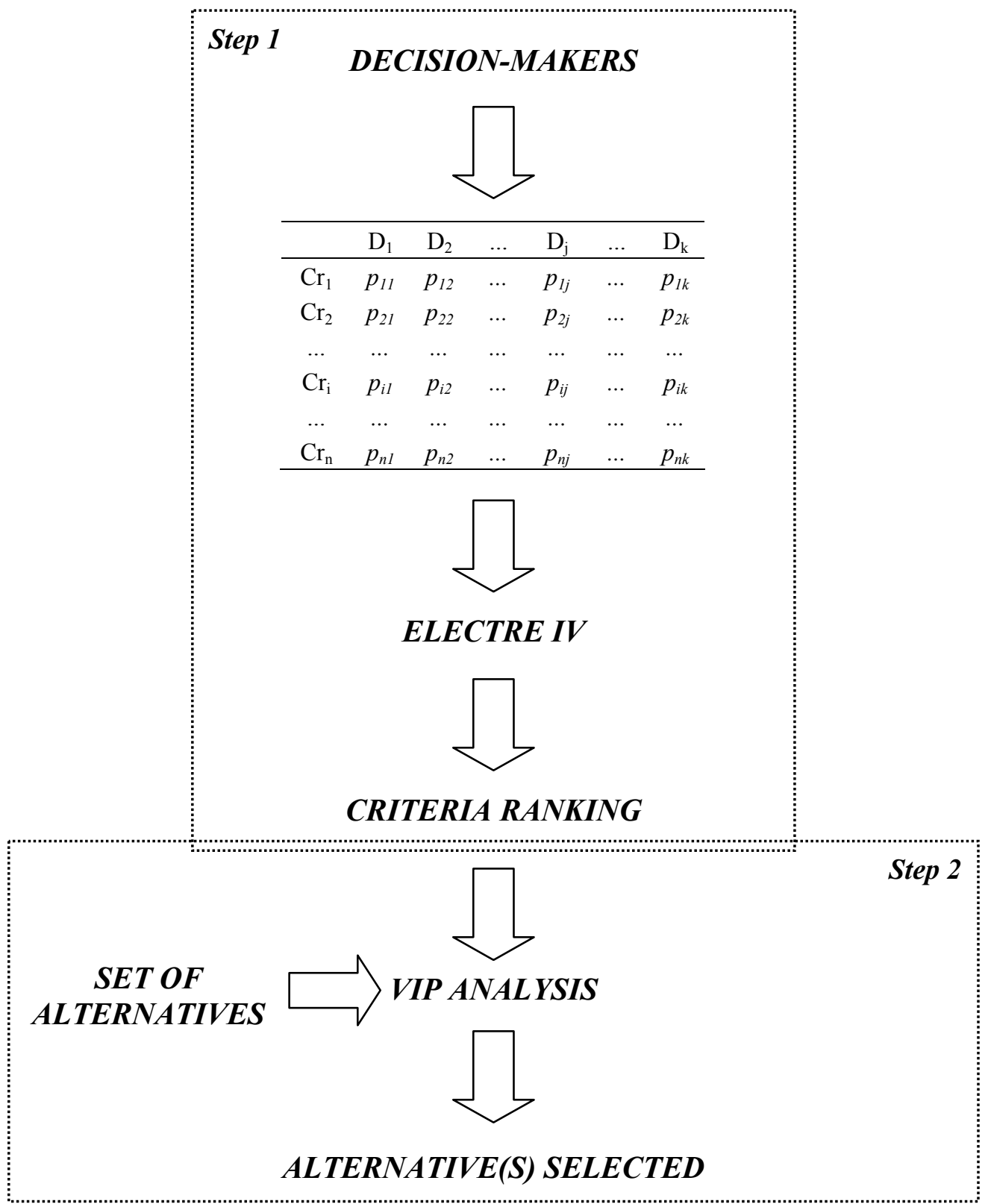

Figure 1 - Multicriteria group decision model with aggregation of the weighting of the decisionmakers on criteria. 


\subsection{Numerical Application}

By way of illustration, the multicriteria group decision model proposed in this section is used in order to select project designers for a given project.

- Step 1

In this first step, as described previously, the decision-makers are described as criteria and the criteria as alternatives, as presented in Tables 2 and 3 below:

Table 2 - Description of criteria.

\begin{tabular}{cl}
\hline Code & \multicolumn{1}{c}{ Criteria } \\
\hline $\mathrm{Cr}_{1}$ & Representative of the Dept of Engineering (technical and maintenance engineer); \\
$\mathrm{Cr}_{2}$ & Representative of the Dept of Engineering (quality engineer); \\
$\mathrm{Cr}_{3}$ & Representative of the Dept of Engineering (security and environment engineer); \\
$\mathrm{Cr}_{4}$ & Representative of the Dept of Acquisitions (budget division); \\
$\mathrm{Cr}_{5}$ & Representative of the Dept of Acquisitions (contracts division). \\
\hline
\end{tabular}

Table 3 - Description of alternatives.

\begin{tabular}{cl}
\hline Code & \multicolumn{1}{c}{ Alternatives } \\
\hline $\mathrm{A}_{1}$ & Cost \\
$\mathrm{A}_{2}$ & Culture \\
$\mathrm{A}_{3}$ & Design \\
$\mathrm{A}_{4}$ & Quality \\
$\mathrm{A}_{5}$ & Deadline \\
$\mathrm{A}_{6}$ & Experience \\
\hline
\end{tabular}

Next, each decision-maker establishes the weights of the criteria. Table 4, below, presents the matrix for evaluating the alternatives in relation to the criteria, comprising the weights attributed by each decision-maker.

Table 4 - Evaluation matrix.

\begin{tabular}{cccccc}
\hline & $\mathrm{Cr}_{1}$ & $\mathrm{Cr}_{2}$ & $\mathrm{Cr}_{3}$ & $\mathrm{Cr}_{4}$ & $\mathrm{Cr}_{5}$ \\
\hline $\mathrm{A}_{1}$ & 0.158 & 0.100 & 0.455 & 0.286 & 0.158 \\
$\mathrm{~A}_{2}$ & 0.053 & 0.150 & 0.000 & 0.071 & 0.053 \\
$\mathrm{~A}_{3}$ & 0.211 & 0.300 & 0.000 & 0.071 & 0.211 \\
$\mathrm{~A}_{4}$ & 0.211 & 0.100 & 0.091 & 0.143 & 0.211 \\
$\mathrm{~A}_{5}$ & 0.158 & 0.050 & 0.364 & 0.286 & 0.158 \\
$\mathrm{~A}_{6}$ & 0.211 & 0.300 & 0.091 & 0.143 & 0.211 \\
\hline
\end{tabular}


For the application of ELECTRE IV, it is necessary to determine the thresholds of indifference $(q)$ and preference $(p)$ for each criterion, as presented in Table 5. Each decisionmaker defines these parameters with the support of the analyst. For all the criteria (decisionmakers), the threshold of indifference is equal to zero, i.e. the alternatives are only indifferent if their evaluations are equal. The strict preference of one alternative in relation to the other is given if the difference between the evaluations is greater than the defined threshold of preference. Between these two thresholds, a weak preference is given of one alternative over the other.

Table 5 - Thresholds of indifference and preference.

\begin{tabular}{cll}
\hline Criteria & $\boldsymbol{q}$ & \multicolumn{1}{c}{$\boldsymbol{P}$} \\
\hline $\mathrm{Cr}_{1}$ & 0 & 0.167 \\
$\mathrm{Cr}_{2}$ & 0 & 0.053 \\
$\mathrm{Cr}_{3}$ & 0 & 0.05 \\
$\mathrm{Cr}_{4}$ & 0 & 0.182 \\
$\mathrm{Cr}_{5}$ & 0 & 0.143 \\
\hline
\end{tabular}

If we apply ELECTRE IV, the following ranking is obtained:

Table 6 - Alternatives ranking.

\begin{tabular}{cc}
\hline Ranking & Alternative \\
\hline $1^{\mathrm{o}}$ & $\mathrm{A}_{6}$ \\
$2^{\mathrm{o}}$ & $\mathrm{A}_{3}$ \\
$3^{\mathrm{o}}$ & $\mathrm{A}_{1}, \mathrm{~A}_{5}$ \\
$4^{\mathrm{o}}$ & $\mathrm{A}_{4}$ \\
$5^{\mathrm{o}}$ & $\mathrm{A}_{2}$ \\
\hline
\end{tabular}

Thus, in accordance with the preferences of the decision-makers, the criteria considered for the second stage of the multi-criteria model in the process of pre-selection, the following ranking was obtained: experience $>$ design $>\cos t=$ deadline $>$ quality $>$ culture.

\subsubsection{Selection of project designers}

The matrix of evaluation of the alternatives regarding criteria is presented in Table 7.

Thus, a decision-making matrix $D=\left[d_{i j}\right]$ is defined, where the element $d_{i j}(i=1, \ldots, n ; j=1, \ldots, p)$ represents the evaluation of the performance of the alternative $a_{i}$ in accordance with criterion $c_{j}$. 
Table 7 - Matrix for evaluating the alternatives.

\begin{tabular}{lcccccc}
\hline & $\mathbf{C r}_{\mathbf{1}}$ & $\mathbf{C r}_{\mathbf{2}}$ & $\mathbf{C r}_{\mathbf{3}}$ & $\mathbf{C r}_{\mathbf{4}}$ & $\mathbf{C r}_{\mathbf{5}}$ & $\mathbf{C r}_{\mathbf{6}}$ \\
\hline Company 1 & 0.10 & 5 & 4 & 4 & 0.100 & 8 \\
Company 2 & 0.15 & 2 & 2 & 4 & 0.050 & 20 \\
Company 3 & 0.05 & 3 & 3 & 3 & 0.100 & 22 \\
Company 4 & 0.15 & 1 & 2 & 3 & -0.050 & 15 \\
Company 5 & 0.03 & 1 & 1 & 4 & 0.150 & 6 \\
Company 6 & -0.03 & 4 & 4 & 3 & 0.200 & 10 \\
Company 7 & 0.05 & 3 & 5 & 3 & 0.100 & 5 \\
\hline
\end{tabular}

Assuming that all the values $d_{i j}$ should be from zero to one, so that each criterion may have the same variation of measurement, the elements of the matrix $D=\left[d_{i j}\right]$ are transformed into an element of the matrix $G=\left[g_{i j}\right]$, using:

$$
\begin{aligned}
& g_{i j}=\frac{d_{i j}-d_{j}^{\min }}{d_{j}^{\max }-d_{j}^{\min }}, \text { for the criteria to be maximized, and } \\
& g_{i j}=\frac{d_{j}^{\max }-d_{i j}}{d_{j}^{\max }-d_{j}^{\min }}, \text { for the criteria to be minimized, }
\end{aligned}
$$

Where $d_{j}^{\max }$ and $d_{j}^{\min }$ are, respectively, the maximum and minimum values, obtained in the set of alternatives for criterion $c_{j}$.

The matrix of normalized evaluation can be seen as in Table 8 .

Table 8 - Matrix of normalized evaluation.

\begin{tabular}{ccccccc}
\hline & $\mathbf{C r}_{\mathbf{1}}$ & $\mathbf{C r}_{\mathbf{2}}$ & $\mathbf{C r}_{\mathbf{3}}$ & $\mathbf{C r}_{\mathbf{4}}$ & $\mathbf{C r}_{\mathbf{5}}$ & $\mathbf{C r}_{\mathbf{6}}$ \\
\hline Company 1 & 0.278 & 1.000 & 0.750 & 1 & 0.400 & 0.176 \\
Company 2 & 0.000 & 0.250 & 0.250 & 1 & 0.600 & 0.882 \\
Company 3 & 0.556 & 0.500 & 0.500 & 0 & 0.400 & 1.000 \\
Company 4 & 0.000 & 0.000 & 0.250 & 0 & 1.000 & 0.588 \\
Company 5 & 0.667 & 0.000 & 0.000 & 1 & 0.200 & 0.059 \\
Company 6 & 1.000 & 0.750 & 0.750 & 0 & 0.000 & 0.294 \\
Company 7 & 0.556 & 0.500 & 1.000 & 0 & 0.400 & 0.000 \\
\hline
\end{tabular}

Once the matrix of evaluation of the alternatives and the constraint of order of the weights of the criteria are determined, the second stage of the multi-criteria group decision model is begun, with the aim of selecting the Company of project designers.

In order to employ VIP Analysis, it is moreover necessary that the maximum and minimum limits of variation to the weight of each criterion be determined. The decision-makers, interactively with the analyst, establish 0.1 as the minimum limit for each weight and 1 as the 
maximum limit. Therefore, the greatest weight that a criterion may reach is 0.5 , if we consider that those remaining stay at the minimum level, i.e. 0.1.

By means of applying VIP Analysis, it is shown that the alternatives 1, 2 and 3 are the only non-dominated ones, these being the pre-selected companies. As can be verified in Figure 2, alternative 3 is the one that presents a minimum global value above all the others and has a maximum regret less than any of the alternatives. Alternative 6 is not absolutely dominated, meaning that, for some combination of weights it can be better than the alternatives 1,2 and/or 3 .

\begin{tabular}{|l|l|l|l|l|l|}
\hline Alternative & Value & Min Value & Max Value & Max Regret & Dominated? \\
\hline a1 & & 0.431 & 0.601 & 0.265 & \\
\hline a2 & & 0.449 & 0.651 & 0.121 & \\
\hline a3 & & 0.492 & 0.696 & 0.108 & \\
\hline a4 & & 0.296 & 0.429 & 0.294 & YES [Abs) \\
\hline a5 & & 0.204 & 0.347 & 0.479 & YES [Abs) \\
\hline a6 & & 0.397 & 0.552 & 0.299 & YES \\
\hline a7 & & 0.246 & 0.453 & 0.45 & YES (Abs) \\
\hline
\end{tabular}

Figure 2 - Summary of the results of the VIP Analysis.

Figure 3 illustrates the ranking of the alternatives according to the minimum global value. It is verified that alternative 3 is the one that presents the greatest global minimum, in addition to alternatives 4,5 and 7 presenting a global maximum value lower than the minimum of alternative 3 , being, these therefore, being considered absolutely dominated.

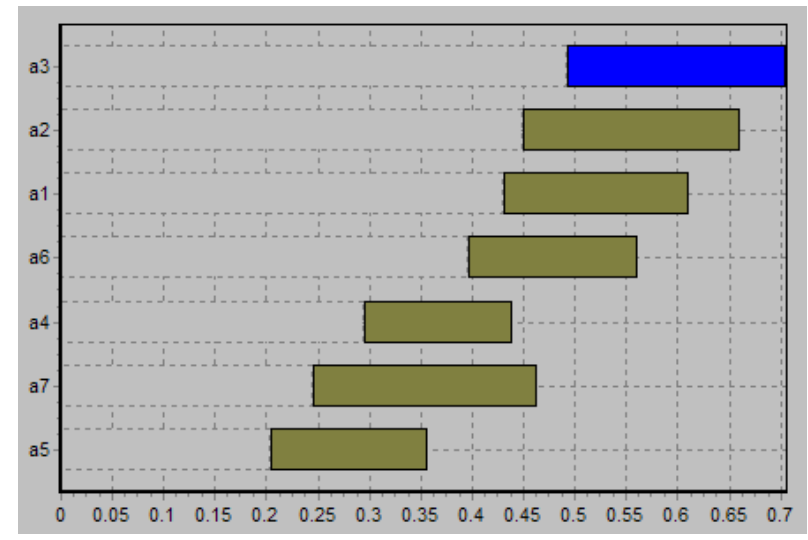

Figure 3 - Amplitude of global value of the alternatives - project designers.

The table of comparison pair by pair between the alternatives is presented in Figure 4 . The cells of this matrix show the difference of value between the pairs of alternatives. The lines represent the advantage of one alternative in relation to the other, while the columns represent the disadvantage of one in relation to the other. Thus, it is seen that Company 3 is the one that offers the greatest advantage in relation to the other Companies, in addition to having the least regret, should a wrong alternative be chosen. 


\begin{tabular}{|l|l|l|l|l|l|l|l|}
\hline & $\mathrm{a} 1$ & $\mathrm{a} 2$ & $\mathrm{a} 3$ & $\mathrm{a} 4$ & $\mathrm{a} 5$ & $\mathrm{a} 6$ & $\mathrm{a} 7$ \\
\hline $\mathrm{a} 1$ & & 0.104 & 0.108 & 0.294 & 0.341 & 0.135 & 0.191 \\
\hline $\mathrm{a} 2$ & 0.22 & & 0.025 & 0.232 & 0.435 & 0.254 & 0.405 \\
\hline $\mathrm{a} 3$ & 0.265 & 0.121 & & 0.277 & 0.479 & 0.299 & 0.45 \\
\hline $\mathrm{a} 4$ & -0.012 & -0.1 & -0.12 & & 0.203 & 0.022 & 0.173 \\
\hline $\mathrm{a} 5$ & -0.215 & -0.16 & -0.145 & 0.016 & & -0.096 & -0.029 \\
\hline $\mathrm{a} 6$ & 0.031 & 0.103 & -0.018 & 0.256 & 0.284 & & 0.151 \\
\hline $\mathrm{a} 7$ & -0.068 & 0.004 & -0.083 & 0.158 & 0.241 & 0.014 & \\
\cline { 1 - 2 } Megret: & 0.265 & 0.121 & 0.108 & 0.294 & 0.479 & 0.299 & 0.45 \\
\hline
\end{tabular}

Figure 4 - Matrix of confrontation.

For the final selection of these Companies, interviews are held, with the aim of clarifying some questions and explaining what the final selection will be like.

The Companies receive the specifications to draw up the projects, and have to present their draft projects to the clients' representatives. The Company which best meets the expectations of the engineering representatives during the presentation of the draft project, which, when presented, should cover all the aspects formally requested, is the one selected.

It is not necessary to conduct a sensitivity analysis a posteriori, since all the combinations of weights considered acceptable by the decision-makers are investigated, thus making it possible for a more robust conclusion to be obtained.

\section{Conclusions}

Given the complexity of project management, which has been increasing over the years, a growing emphasis has been being given to the development of new forms for selecting suppliers, with the aim of minimizing conflicts between the different actors involved, obtaining better relationships between them and meeting the project's objectives, all of which are generally centered on delivery of the final product at the least possible cost, with quality, abiding by deadlines and the scope defined, in such a way as to obtain client satisfaction.

Therefore, this paper has presented a proposal for a multi-criteria group decision model for selecting project suppliers, by means of using VIP Analysis and ELECTRE IV methods, which, if used appropriately, will result in the selection of suppliers who will enter the project team in accordance with the client's expectations. A problem structuring was presented and used as a reference to the numerical application. The problem presented is a specific illustration and may not be applicable to other situations.

It is important to point out that the objectives of this study were achieved since the model presented can be used for problems where there is divergence about the preferences of the decision-makers.

In general, decisions related to the selection of suppliers involve a group of people, from different departments of the organization, in order to represent the client's interests. Many studies found in the literature do not tackle the question of group decision and consider decision-making only as if a single person were responsible for this decision, which does not correspond to a real situation.

Thus the model developed, in the context applied, indicates the suppliers who demonstrate the greatest commitment to the client's objectives. 


\section{Acknowledgements}

This study is part of a research program funded by the Brazilian Research Council (CNPq).

\section{References}

(1) Belton, V. \& Stewart, J. (2002). Multiple criteria decision analysis - an integrated approach. Kluwer Academic Publishers, London.

(2) Beynon, M.J. (2006). The Role of the DS/AHP in identifying inter-group alliances and majority rule within group decision making. Group decision and negotiation, 15(1), 21-42.

(3) Brown, D.C. et al. (2001). New project procurement process. Journal of management in engineering, 17(4), 192-201.

(4) British Standard Institute. (2000). Guide to project management. BS 6079. BSI. UK.

(5) Campos, V.R \& Almeida, A.T. (2006). Modelo multicritério de decisão para localização de Nova Jaguaribara com VIP Analysis. Pesquisa Operacional, 26(1), 91-107.

(6) Clímaco, J.C. \& Dias, L.C. (2005). An approach to support negotiation processes with imprecise information multicriteria additive models. In: Workshop on formal and informal information exchange in negotiations. Proceedings... School of Information Technology and Engineering, University of Ottawa.

(7) Colson, G. (2000). The OR's prize winner and the software ARGOS: how a multijudge and multicriteria ranking GDSS helps a jury to attribute a scientific award. Computers \& Operations Research, 27, 741-755.

(8) Costa, J.P. et al. (2003). The AGAP System: A GDSS for project analysis and evaluation. European Journal of Operational Research, 145(2), 287-303.

(9) Dias, L.C. \& Clímaco, J.N. (2000). Additive aggregation with variable interdependent parameters: the VIP Analysis software. Journal of the Operational Research Society, 51, 1070-1082.

(10) Easley, R.F.; Valacich, J.S. \& Venkataramanan, M.A. (2000). Capturing group preferences in a multicriteria decision. European Journal of Operational Research, 125, 73-83.

(11) Edwards, W. \& Barron, F.H. (1994). SMARTS and SMARTER: Improved Simple Methods for Multiattribute Utility Measurement. Organizational Behavior and Human Decision Processes, 60, 306-325.

(12) Gomes, L.M.; Gomes, C.F.S. \& Almeida, A.T. (2002). Tomada de decisão gerencial: enfoque multicritério. Atlas, São Paulo.

(13) Humphreys, P. \& Garrick, J. (2006). The evolution of group decision support systems to enable collaborative authoring of outcomes. The Journal of General Evolution, 62(3), 193-222.

(14) Jelassi, T.; Kersten, G. \& Ziont, S. (1990). An introduction to group decision and negotiation support. In: Readings in multiple criteria decision aid [edited by Bana e Costa], Springer-Verlag, Berlin, 537-568. 
(15) Jiménez, M. \& Polasek, W. (2003). E-democracy and knowledge. A multicriteria framework for the new democratic era. Journal multicriteria decision analysis, 12, 163-176.

(16) Keeney, R. (1992). Value-Focused Thinking. Harvard University Press, London.

(17) Leyva-López, J.C. \& Fernández-Gonzalez, E. (2003). A new method for group decision support based on ELECTRE III methodology. European Journal of Operational Research, 26(3).

(18) Macharis, C. \& Brans, J.P. (1998). The GDSS PROMETHEE procedure. Journal of Decision Systems, 7, 283-307.

(19) Matsatsinis, N.F.; Grigoroudis, E. \& Samaras, A. (2005). Aggregation and disaggregation of preferences for collective decision-making. Group decision and negotiation, 14(3), 217-232.

(20) Merna, A. \& Smith, N.J. (1990). Bid evaluation for UK public-sector construction contracts. In: Proceedings of the Institution of Civil Engineers part 1 - design and construction, 88, 91-105.

(21) PMI - Project Management Institute. (2004). A guide to the project management body of knowledge - PMBOK Guide, Pennsylvania.

(22) Roy, B. \& Hugonnard, J.C. (1982). Ranking of suburbian line extension projects on the Paris metro system by a multicriteria method. Transpn. Res., 16(4), 301-312.

(23) Smith, R.C. (1991). Estimating and tendering for building work. Longman Scientific and Technical, UK.

(24) Vincke, P. (1992). Multicriteria decision-aid. Wiley, Bruxelles.

(25) Young, H.P. (1991). Negotiation analysis. The University of Michigan Press, Michigan. 